\title{
Effect of polymer concentration on the lifetime and transmittance behavior of a self-oscillating polymer chain with a high lower critical solution temperature
}

\author{
Tomoka Nakazumi ${ }^{1}$ and Yusuke Hara ${ }^{1, a}$ \\ ${ }^{1}$ Research Institute for Sustainable Chemistry, ISC, National Institute of Advanced Industrial Science and Technology, AIST, \\ Central 5-2, 1-1-1 Higashi, Tsukuba 305-8565, Japan.
}

\begin{abstract}
In this study, we investigated the lifetime and self-oscillating behavior of a polymer chain with a high lower critical solution temperature (LCST). The polymer chain comprised 4-vinyl-4'-methyl-2,2'-bipyridinebis(2,2'bipyridine)bis(hexafluorophosphate) ruthenium as catalyst for the Belousov-Zhabotinsky reaction and Nethylacrylamide as the polymer main-chain with a high LCST when compared to N-isopropylacrylamide. We demonstrated that the self-oscillating behavior was significantly affected by the polymer concentration and measuring temperature. Moreover, we established that the lifetime of the transmittance self-oscillation can be predicted from the polymer concentration and measuring temperature.
\end{abstract}

\section{Introduction}

The Belousov-Zhabotinsky (BZ) reaction is a famous self-oscillating reaction that occurs under constant temperature conditions [1-8]. The behavior of this reaction differs under unstirred and stirred conditions. When unstirred, the reaction period (time scale: dozens of seconds) and space scale (several millimeters) allow complex patterns originating from the transition-metal catalyst to be observed with the naked eye. Therefore, the chemical waves and patterns of the BZ reaction have been much investigated as a model for spatiotemporal structure formation by scientists in various fields including mathematics, physics, and chemistry. Under strong acid conditions comprising nitric acid $\left(\mathrm{HNO}_{3}\right)$ or sulfuric acid $\left(\mathrm{H}_{2} \mathrm{SO}_{4}\right)$, the organic substrate [malonic acid (MA)] in the BZ reaction is oxidized by an oxidizing agent [sodium bromate $\left(\mathrm{NaBrO}_{3}\right)$ ] in the presence of a transition-metal catalyst.

In this study, we synthesized a self-oscillating polymer chain, covalently bonded to the transition-metal catalyst moiety $\left[\mathrm{Ru}(\mathrm{bpy})_{3}\right]$, to undergo a periodical transmittance change induced by the BZ reaction [9-21]. In this latter reaction, a periodical change in the solubility of the polymer chain was synchronized with the periodical redox change in the $\mathrm{Ru}(\mathrm{bpy})_{3}$ moiety. This occurred because the $\mathrm{Ru}(\mathrm{bpy})_{3}$ moiety exhibits different solubilities in its reduced and oxidized states. Thus, the reduced $\mathrm{Ru}(\mathrm{bpy})_{3}$ moiety in the self-oscillating polymer chain is hydrophobic compared to the oxidized $\mathrm{Ru}(\mathrm{bpy})_{3}$ moiety. This difference in solubility originates from the transmittance self-oscillation induced by the BZ reaction. No color changes were observed between the reduced and

\footnotetext{
a Corresponding author: y-hara@aist.go.jp
}

oxidized $\mathrm{Ru}(\mathrm{bpy})_{3}$ during transmittance self-oscillation measurements. Thus, the isosbestic points of the polymer solution in the reduced and oxidized states were detected by a spectrophotometer. We concluded that transmittance self-oscillation is due to the soluble-insoluble change in the polymer solution in the reduced and oxidized states induced by the $\mathrm{BZ}$ reaction.

In this investigation, we adopted poly $(\mathrm{N}$ ethylacrylamide) [poly(NEAAm), Figure 1] as a selfoscillating polymer main-chain with a high lower critical solution temperature (LCST). This polymer chain undergoes transmittance self-oscillation in a wide temperature range when compared to the conventional self-oscillating polymer chain comprising a poly $(\mathrm{N}$ isopropylacrylamide) [poly(NIPAAm)] main-chain [2223]. Previous investigations have employed the latter self-oscillating main-chain with an LCST of $\sim 32{ }^{\circ} \mathrm{C}[10$ 21]. Moreover, for the NIPAAm-based self-oscillating polymer chain \{poly[NIPAAm-co-Ru(bpy) 3 \}, the LCST in the reduced state is lower than that of poly(NIPAAm) because of the low solubility of the reduced $\mathrm{Ru}(\mathrm{bpy})_{3}$ moiety [19]. Therefore, the self-oscillating polymer chain cannot undergo self-oscillation at high temperatures. This occurs because the NIPAAm-based self-oscillating polymer chain is easily aggregated in the reduced state that originates from the hydrophobic main-chain and interactions between the hydrophobic reduced $\mathrm{Ru}(\mathrm{bpy})_{3}$ moiety. At high temperatures, the aggregation of the selfoscillating polymer chain is much faster because of the lower LCST of the polymer chain. Therefore, the selfoscillating polymer solution cannot disaggregate as the self-oscillating polymer solution changes from the reduced state to the oxidized state; this latter state 
originates from the higher hydrophobic nature of the polymer main-chain.

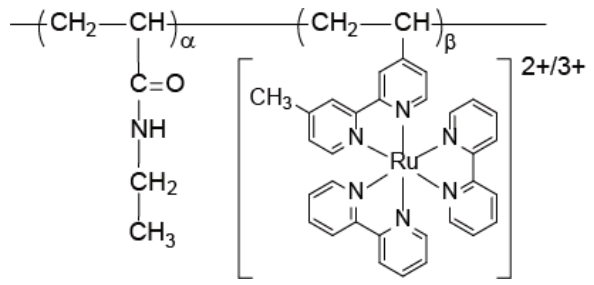

Figure 1. Chemical structure of the self-oscillating polymer chain $\left\{\right.$ poly $\left.\left[\mathrm{NEAAm}-c o-\mathrm{Ru}(\text { bpy })_{3}\right]\right\} . \mathrm{NEAAm}=\mathrm{N}-$ ethylacrylamide; Ru(bpy) $3=4$-vinyl-4' - methyl-2,2' bipyridinebis $\left(2,2^{\prime}\right.$ bipyridine)bis(hexafluorophosphate) ruthenium.

In this study, to determine the activation energy, we measured the transmittance self-oscillation of a poly[NEAAm-co-Ru(bpy) $)_{3}$ ] aqueous solution comprising the three BZ substrates (sulfuric acid, malonic acid, and sodium bromate) at high temperatures. We also examined the effect of the polymer concentration on the selfoscillating behavior and the lifetime of the transmittance self-oscillation.

\section{Experimental section}

\subsection{Synthesis of poly[NEAAm-co-Ru(bpy $\left.)_{3}\right]$}

Poly[NEAAm-co-Ru(bpy) $)_{3}$ (Figure 1) was synthesized by free-radical polymerization at $83{ }^{\circ} \mathrm{C}$ for $5 \mathrm{~h}$ under $\mathrm{N}_{2}$ bubbling. 4-vinyl-4'-methyl-2,2' -bipyridinebis(2, $2^{\prime}$ bipyridine)bis(hexafluorophosphate) ruthenium $\left[\mathrm{Ru}(\mathrm{bpy})_{3} ; 1.25 \mathrm{~g}\right]$, NEAAm (10.7 g), and 2,2'-azobis(2methylbutyronitrile) $(0.63 \mathrm{~g})$ were dissolved in an ethanol/water $(1: 1 ; 125.3 \mathrm{~g})$ mixture. The resultant poly[NEAAm-co-Ru(bpy $)_{3}$ ] aqueous solution was subsequently dialyzed against ethanol for $10 \mathrm{~d}$ to remove any unreacted monomers and the initiator.

\subsection{Measurement of transmittance self- oscillation}

Polymer solutions comprising the three BZ substrates [malonic acid $(0.09 \mathrm{M})$, sodium bromate $(0.5 \mathrm{M})$, and sulfuric acid $(0.4 \mathrm{M})]$ were prepared. The self-oscillating behavior of the polymer solution was measured using a spectrophotometer at $570 \mathrm{~nm}$; this is the isosbestic point of the polymer solutions in the reduced and oxidized states. The transmittance self-oscillation was detected by the spectrophotometer while stirring.

\section{Results and Discussion}

Figure 2 illustrates the transmittance self-oscillating behavior of the poly[NEAAm-co-Ru(bpy) $)_{3}$ ] solutions with a fixed concentration of the three BZ substrates at (A) $23{ }^{\circ} \mathrm{C}$ and (B) $28{ }^{\circ} \mathrm{C}$. The self-oscillating behavior of the polymer solutions was significantly affected by the measuring temperature. In previous studies, Hara measured the LCST of the poly[NEAAm-co-Ru(bpy $\left.)_{3}\right]$ solution in the reduced and oxidized states [22-23]. The LCST values of these solutions in the reduced and oxidized states were determined as $16{ }^{\circ} \mathrm{C}$ and $44{ }^{\circ} \mathrm{C}$, respectively. This difference in solubility originated from the transmittance self-oscillation induced by the BZ reaction. In the oxidized state, the LCST was higher than that in the reduced state. The higher LCST in the oxidized $\mathrm{Ru}(\mathrm{bpy})_{3}$ moiety allowed self-oscillation at higher temperatures when compared to the NIPAAmbased self-oscillating polymer solution.
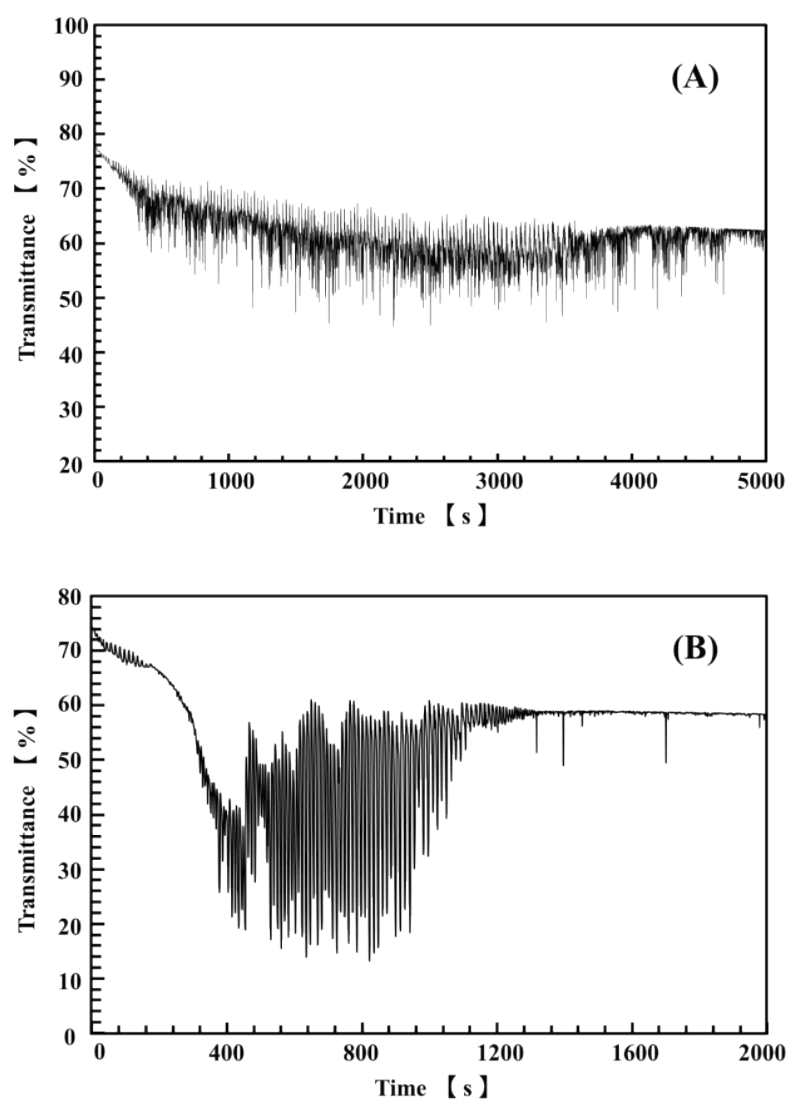

Figure 2. Transmittance self-oscillation for a $0.5 \mathrm{wt} . \%$ poly[NEAAm-co-Ru(bpy) 3 ] aqueous solution with a fixed initial concentration of sulfuric acid $(0.4 \mathrm{M})$, sodium bromate $(0.5 \mathrm{M})$, and malonic acid $(0.09 \mathrm{M})$ under fixed temperatures of (A) $23{ }^{\circ} \mathrm{C}$ and (B) $28^{\circ} \mathrm{C}$. NEAAm $=$ N-ethylacrylamide; $\mathrm{Ru}(\mathrm{bpy})_{3}=4$-vinyl-4' -methyl-2,2' bipyridinebis(2,2'bipyridine)bis(hexafluorophosphate) ruthenium.

Figure 3 demonstrates the Arrhenius dependence of the transmittance self-oscillation of the NEAAm-based polymer solutions with fixed concentrations of the three BZ substrates; the period of self-oscillation decreased with an increase in temperature. The activation energy of the polymer solutions was calculated as $86.7 \mathrm{~kJ} / \mathrm{mol}$. This value was higher than that of the poly[NEAAm-co$\mathrm{Ru}(\mathrm{bpy})_{3}$ ] solution including nitric acid as the strong acid for the BZ reaction. Thus, since sulfuric acid exhibits a smaller oxidizing power than nitric acid, we attributed this difference in activation energy to the different oxidizing power of the strong acid employed. The 
different oxidizing power greatly affected the $\mathrm{BZ}$ reaction because the chemical process of the oxidation in the BZ reaction is significantly important and affects the ease of the elementary reaction.

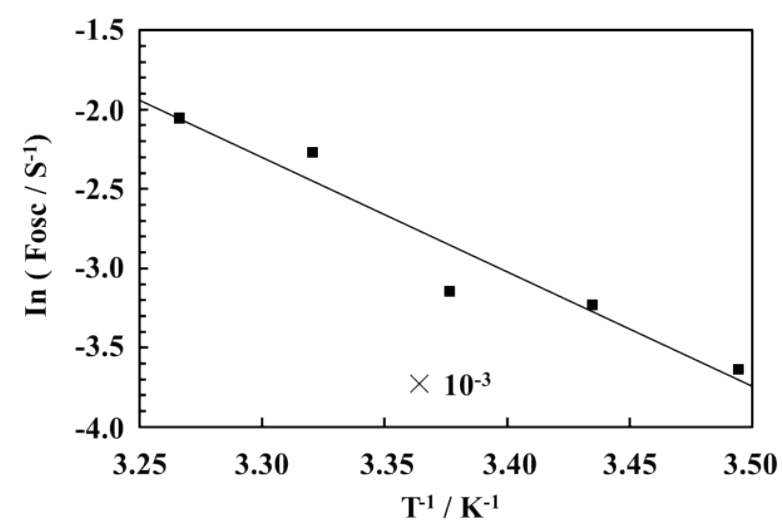

Figure 3. Arrhenius dependence of the self-oscillating frequency (Fosc) on temperature for a poly[NEAAm- $\mathrm{Co}$ $\mathrm{Ru}(\mathrm{bpy})_{3}$ ] solution with fixed concentrations of the three BZ substrates [sulfuric acid $(0.4 \mathrm{M})$, malonic acid $(0.09 \mathrm{M})$, and sodium bromate $(0.5 \mathrm{M})]$. NEAAm $=\mathrm{N}$-ethylacrylamide; $\mathrm{Ru}(\mathrm{bpy})_{3}=4$-vinyl-4' - methyl-2,2'-bipyridinebis $\left(2,2^{\prime}\right.$ bipyridine)bis(hexafluorophosphate) ruthenium.

Figure 4 represents the relationship between the lifetime of the transmittance self-oscillation and the measuring temperature. The lifetime of the transmittance self-oscillation elongated as the measuring temperature decreased. At higher temperatures, the number of selfoscillations was larger at shorter times because the period of self-oscillation was shorter. Therefore, we considered that the duration of the transmittance self-oscillation for poly[NEAAm-co-Ru(bpy) $)_{3}$ ] was shorter at higher temperatures. This occurred because malonic acid, the energy source of the BZ reaction, was consumed after shorter periods of time at higher temperatures.

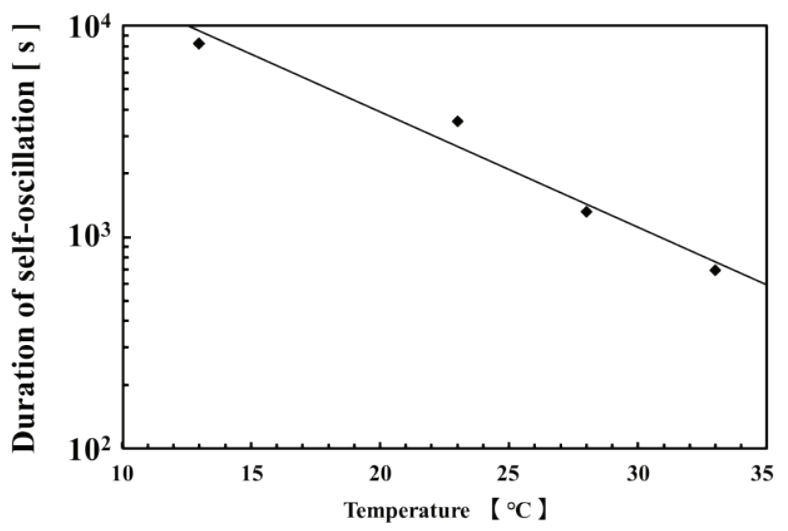

Figure 4. Dependence of the duration time of poly[NEAAm-co$\mathrm{Ru}(\mathrm{bpy})_{3}$ ] solutions as a function of temperature with fixed initial concentrations of sulfuric acid $(0.4 \mathrm{M})$, malonic acid $(0.09 \mathrm{M})$, and sodium bromate $(0.5 \mathrm{M})$. NEAAm $=\mathrm{N}$ ethylacrylamide; $\mathrm{Ru}(\mathrm{bpy})_{3}=4$-vinyl-4'-methyl-2,2'bipyridinebis (2,2' bipyridine)bis(hexafluorophosphate) ruthenium.
Figure 5 displays the effect of the polymer concentration on the self-oscillating behavior. The period of self-oscillation was greatly affected by the polymer concentration. The large noise observed in Figure 5 (A was derived from the carbon dioxide $\left(\mathrm{CO}_{2}\right)$ generated in the $\mathrm{BZ}$ reaction.
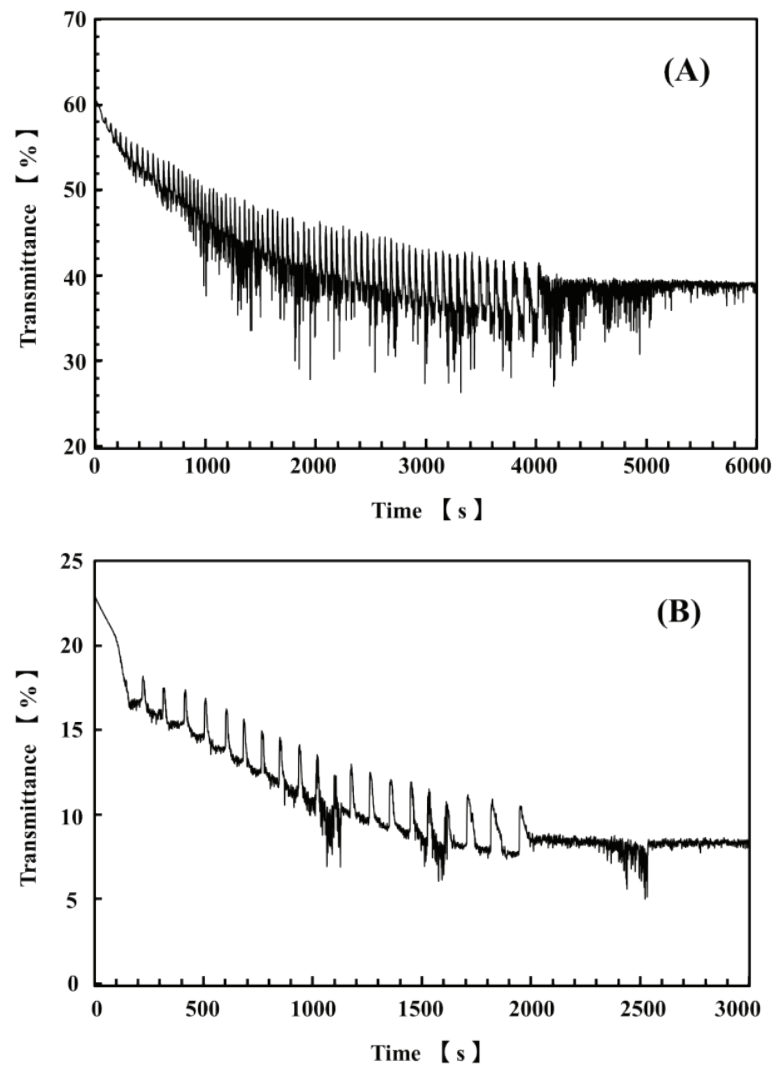

Figure 5. Transmittance self-oscillation for poly[NEAAm-coRu(bpy) 3 ] solutions [(A) 1.0 wt.\% and (B) 3.0 wt. \%] with fixed initial concentrations of sodium bromate $(0.5 \mathrm{M})$, sulfuric acid $(0.4 \mathrm{M})$, and malonic acid $(0.09 \mathrm{M})$ at $13{ }^{\circ} \mathrm{C} . \mathrm{NEAAm}=\mathrm{N}$ ethylacrylamide; $\mathrm{Ru}$ (bpy) $3=4$-vinyl $-4^{\prime}$-methyl $-2,2^{\prime}$ bipyridinebis $\left(2,2^{\prime}\right.$ bipyridine)bis(hexafluorophosphate) ruthenium.

Figure 6 illustrates the relationship between the period of the transmittance self-oscillation and polymer concentration. The period of self-oscillation increased with an increase in polymer concentration. Moreover, when the polymer concentration increased, the viscosity of the polymer solution also increased while the diffusion coefficient of the BZ substrates decreased. Therefore, the period of self-oscillation decreased with an increase in polymer concentration. On the other hand, as the polymer concentration increased, the concentration of the $\mathrm{Ru}(\mathrm{bpy})_{3} \mathrm{BZ}$ reaction catalyst also increased. This result indicated that the $\mathrm{Ru}(\mathrm{bpy})_{3}$ concentration exhibited less influence on the period of the transmittance selfoscillation of the poly[NEAAm-co-Ru(bpy) $)_{3}$ aqueous solution. 


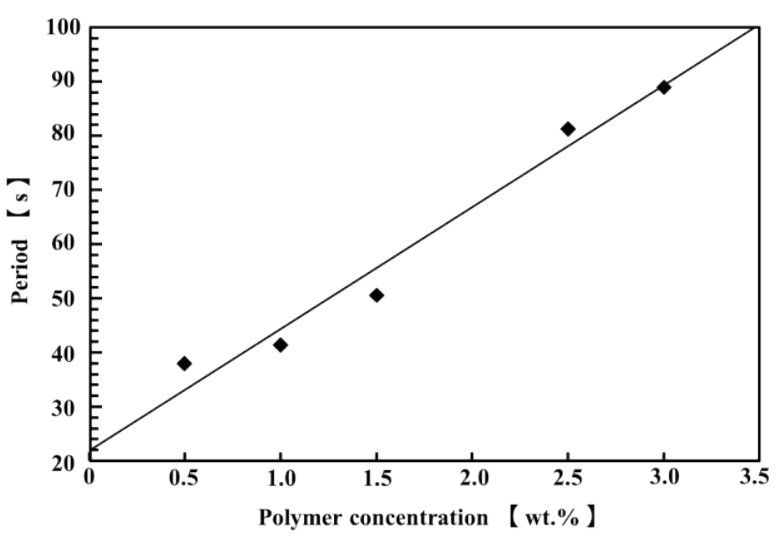

Figure 6. Dependence of the period of the poly[NEAAm- $\mathrm{co}$ $\mathrm{Ru}(\mathrm{bpy})_{3}$ ] solutions as a function of polymer concentration with fixed initial concentrations of sulfuric acid $(0.4 \mathrm{M})$, malonic acid $(0.09 \mathrm{M})$, and sodium bromate $(0.5 \mathrm{M})$ at $13{ }^{\circ} \mathrm{C}$. NEAAm $=\mathrm{N}$-ethylacrylamide; Ru(bpy) $3=4$-vinyl-4' ${ }^{\prime}$-methyl-2,2' bipyridinebis(2,2' bipyridine)bis(hexafluorophosphate) ruthenium.

Figure 7 represents the relationship between the concentration of the poly[NEAAm-co-Ru(bpy) 3 ] solution and the lifetime of the transmittance self-oscillation. The duration time of the self-oscillation was significantly affected by the polymer concentration. As the polymer concentration decreased, the duration time increased. On the other hand, when the polymer concentration increased, the period of self-oscillation also increased. For the 3.0 wt. $\%$ polymer concentration, the period of selfoscillation was longer while the lifetime was shorter. Thus, as the number of self-oscillations decreased, the lifetime of the self-oscillation became shorter. This tendency is the opposite of the trend observed for the plot of the lifetime against measuring temperature (Figures 3 and 4).

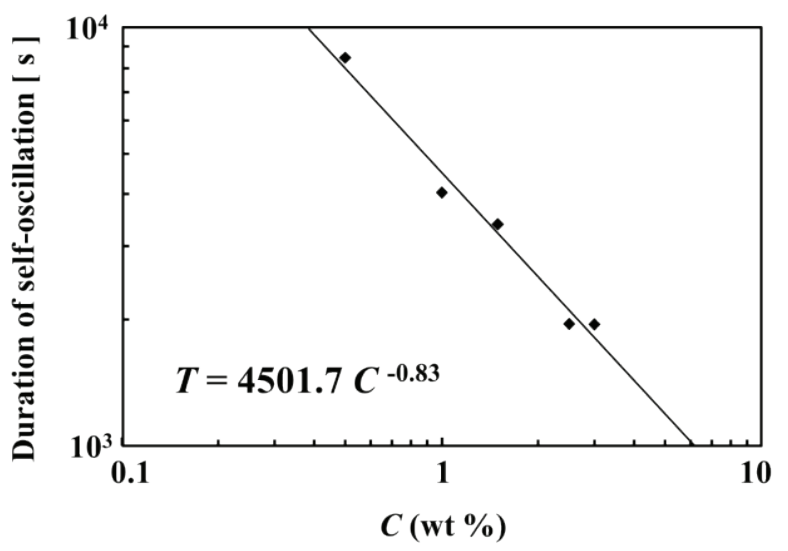

Figure 7. Dependence of the duration time of the poly[NEAAm- $\left.c o-\mathrm{Ru}(\mathrm{bpy})_{3}\right]_{\text {s }}$ solution as a function of polymer concentration, with fixed initial concentrations of sulfuric acid $(0.4 \mathrm{M})$, malonic acid $(0.09 \mathrm{M})$, and sodium bromate $(0.5 \mathrm{M})$ at $13{ }^{\circ} \mathrm{C}$.

\section{Conclusion}

In this study, we demonstrated the effect of the measuring temperature on the transmittance self-oscillating behavior of the poly[NEAAm-co-Ru(bpy $\left.)_{3}\right]$ solution. We established that the period of self-oscillation follows the Arrhenius equation. The activation energy of the polymer solution was determined as $86.7 \mathrm{~kJ} / \mathrm{mol}$. Moreover, the lifetime of the self-oscillation became shorter with an increase in temperature because the malonic acid in the polymer solution was consumed in a shorter time. In addition, we confirmed the influence of the polymer concentration on the self-oscillating behavior and lifetime by changing the polymer concentration. The period of self-oscillation increased when the polymer concentration increased. This result indicated that the diffusion coefficients of the three BZ substrates were significantly affected by the polymer concentration. On the other hand, as the polymer concentration increased, the lifetime of the transmittance self-oscillation became shorter. This occurred because the cycle number and the duration of the self-oscillation decreased as the polymer concentration increased. This trend was the reverse of the trend observed for the change in temperature.

\section{Acknowledgements}

This work was supported by Grants-in-Aid (KAKENHI) for Young Scientists (B) (16K17493, 15K18014) and Scientific Research (B) (17H03209, 15H03827). This work was also carried out under the auspices of the New Energy and Industrial Technology Development Organization (NEDO) of Japan under the Industrial Technology Research Grant Program in 2011.

\section{References}

1. B.P. Belousov, Sb. Ref. Radiat. Med. (Collections of Abstracts on Radiation Medicine, Medgiz, Moscow) 1, 145 (1959)

2. A.N. Zaikin, A.M. Zhabotinsky, Nature 225, 535 (1970)

3. J. Lindsay Oscillations and traveling waves in chemical systems (Eds. R.J. Field, M. Burger, Wiley, New York, 1985)

4. S.K. Scott, Chemical chaos, $1^{\text {st }}$ ed. (Oxford University Press, Oxford, 1991)

5. E.J. Reusser, R.J. Field, J. Am. Chem. Soc. 101, 1063 (1979)

6. G. Nicolis, I. Prigogine, Self-organization in nonequilibrium systems (Wiley, New York, 1977)

7. G. Nicolis, I. Prigogine, Self-Orgainization in nonequilibrium Systems Wiley, New York 27, 1977)

8. J.D. Murray, Mathematical Biology (Springer-Verlag, Berlin, 1990)

9. T. Ishiwatari, M. Kawagishi and M. Mitsuishi, J. Polym. Sci.: Polym. Chem. 22, 2699 (1984)

10. R. Yoshida, T. Sakai, S. Ito, T. Yamaguchi, J. Am. Chem. Soc. 124, 8095 (2002)

11. R. Yoshida, T. Takahashi, T. Yamaguchi and H. Ichijo, J. Am. Chem. Soc. 118, 5134 (1996) 
12. Y. Hara, R. Yoshida, J. Phys. Chem. B 109, 9451 (2005).

13. Y. Hara, R. Yoshida, Langmuir 21, 9773 (2005).

14. Y. Hara, R. Yoshida, J. Chem. Phys. 128, 224904 , (2008).

15. Y. Hara, R. Yoshida, J. Phys. Chem. B 112, 8427 (2008)

16. Y. Hara, R. Yoshida, Macromol. Chem. Phys. 210, 2160 (2009).

17. Y. Hara, R. Yoshida, Macromol. Rapid Commun. 30, 1656 (2009).

18. Y. Hara, H. Mayama, Y. Yamaguchi, Y. Takenaka, R. Fukuda, J. Phys. Chem. B 117, 14351 (2013).

19. Y. Hara, Y. Takenaka, Sens. 14, 1497 (2014).

20. Y. Hara, Y. Yamaguchi, H. Mayama, J. Phys. Chem. B 118, 634 (2014).

21. Y. Hara, K. Fujimoto, H. Mayama, J. Phys. Chem. B 118, 608 (2014).

22. Y. Hara, Adv. Mater. Res. 941, 1208 (2014).

23. Y. Hara, Adv. Mater. Res. 941, 1212 (2014). 